\title{
Interocular transfer in albino and pigmented perinatal guinea pigs'
}

Clarene C. Petre and Charles L. Sheridan

UNIVERSITY OF MISSOURI AND V. A. HOSPITAL, KANSAS CITY

Interocular transfer of a pattern discrimination was measured in albino and pigmented guinea pigs ranging from 1 to 37 days of age when training began. Transfer was unrelated to albinism, but significantly more transfer occurred in a 14 to 37-day old group of $S$ s than in a 1-day old group. These findings are related to previous anatomical and electrophysiological observations concerning the functioning of optic uncrossed fiber systems.

The sparse optic uncrossed fiber system, which is characteristic of rats in general, is especially small and ineffective in albino rats (Lund, 1965; Sheridan \& Shrout, 1966). Corresponding to this, it has been noted that albino rats show little interocular transfer in situations which given rise to high level transfer in rats with pigmented eyes (Sheridan, 1965; Sheridan \& Shrout, 1965). In the present study an attempt was made to determine whether low level interocular transfer is also associated with albinism in a species closely related to the rat-the guinea pig.

Interocular transfer as a function of age was also observed. Rose \& Lindsley (1965), using kittens, have shown that evoked potentials coming from the uncrossed optic fiber bundles develop at a later age than potentials from crossed bundles. If Rose and Lindsley's findings have phylogenetic generality and if the effectiveness of the uncrossed systems is an important determinant of interocular transfer in guinea pigs, interocular equivalence should develop over the first few days or weeks of life. In guinea pigs it should be possible to observe this behaviorally because they are sufficiently well developed for training almost immediately after birth.

\section{Subjects}

Ss were 15 guinea pigs with unpigmented and nine with pigmented eyes. Their ages at the start of pretraining ranged from 1 to 37 days.

Apparatus

The apparatus was a two-choice discrimination box. It utilized shock motivation, and consisted of a start box, runway, choice point with two alternative entryways, and a goalbox.

Procedure

Ss were pretrained to run to the goal box and to knock over gray stimulus doors which blocked the goal box entryways. In $14 \mathrm{Ss}$ the left eye and in $10 \mathrm{Ss}$ the right eye was then occluded with a black contact occluder which covered the eye to its base. Ss were trained monocularly to discriminate horizontal from vertical $1 / 2$ in. stripes with the horizontal stripes correct for 14 Ss and the vertical correct for 10 Ss. Position of the
Table 1. Median percentages of second-eye savings in trials and in errors to criterion and median percentages correct with both eyes occluded for albino and pigmented 1 day old guinea pigs.

\begin{tabular}{lccc} 
& $\begin{array}{c}\text { (Trials) } \\
\text { Median \% } \\
\text { Savings }\end{array}$ & $\begin{array}{c}\text { (Errors) } \\
\text { Median \% } \\
\text { Savings }\end{array}$ & $\begin{array}{c}\text { Median \% Correct } \\
\text { Binocular Occlusion }\end{array}$ \\
\hline Albino & 55.6 & 64.1 & 50.0 \\
Pigmented & 70.0 & 76.4 & 50.0 \\
\hline
\end{tabular}

correct stimulus was determined by a Gellermann series. Approximately 20 trials per day were given until a criterion of 18 correct responses in 20 consecutive trials had been reached. After Ss had reached criterion, they were "overtrained" by running them to an additional $9 / 10$ criterion on the same eye, then the occluder was removed and attached to the opposite eye and Ss were run to the $18 / 20$ criterion on the second eye. After completion of training on the second eye, all Ss were run 10 trials with both eyes occluded.

Results

The last columns of Tables 1 and 2 show that Ss performed at chance levels when occluded binocularly.

Median second-eye percentages of savings in trials and in errors for albino and pigmented Ss which were 1 day old when pretraining began are given in Table 1 . It was clear by inspection of the raw data that differences in savings between albino and pigmented Ss in no case approached acceptable levels of statistical reliability.

Median percentages of second-eye savings in trials and in errors to criterion for the various age groups are given in Table 2. High-level transfer occurred in Ss 14 days of age or older. Significantly more interocular transfer occurred in the 14-37 day group than in the one-day-old group, whether comparisons of savings in trials or in errors were made (Trials: Mann-Whitney $\mathrm{U}=11, \mathrm{n}_{1}=5, \mathrm{n}_{2}=15, \mathrm{p}=.02$; Errors: $\mathrm{U}=5, \mathrm{n}_{1}=5$, $\left.\mathrm{n}_{2}=15, \mathrm{p}<.02\right)$. These and all other $\mathrm{p}$ values presented here are two-tailed.

Some indications of the high-level transfer charac-

Table 2. Median percentages of second-eye savings in trials and in errors to criterion and median percentages correct with both eyes occluded by age group.

\begin{tabular}{cccc} 
& $\begin{array}{c}\text { (Trials) } \\
\text { Median \% } \\
\text { Sovings }\end{array}$ & $\begin{array}{r}\text { (Errors) } \\
\text { Median \% } \\
\text { Sovings }\end{array}$ & $\begin{array}{r}\text { Median \% Correct } \\
\text { Binocular Occlusion }\end{array}$ \\
\hline Age (Days) & & & \\
$1(\mathrm{~N}=15)$ & 60.1 & 69.9 & 50.0 \\
$3(\mathrm{~N}=4)$ & 54.7 & 50.0 & 50.0 \\
$14-37(\mathrm{~N}=5)$ & 100.0 & 100.0 & 50.0 \\
\hline
\end{tabular}


teristic of older Ss appeared in the 3-day group, in which two Ss had almost no savings and the other two showed perfect transfer. No $S$ in the 1-day group exhibited perfect transfer.

Since it would be possible to attribute age differences in interocular transfer to variations in stability of performance as a function of age, the number of trials to the $9 / 10$ overtraining criterion after having met the $18 / 20$ criterion was examined. In each age group, the median number of trials was zero.

First-eye acquisition was significantly more rapid in the 14-37 day group ( 40 trials and 18 errors to criterion) than in the 1-day group (89 trials and 40 errors to criterion). For trials, $U=11, p=.02$ and for errors, $U=13, p<.05$.

\section{Discussion}

The present study fails to support the generality of the relationship, even across rodents, between albinism and interocular transfer. However, there is a relationship between age and the development of interocular equivalence which parallels the development of ipsilateral optic fiber system evoked response observed by Rose \& Lindsley (1965) in kittens. It would be interesting to learn whether the late development of ipsilateral response can be reproduced in evoked potential studies done on guinea pigs.

The high-level interocular transfer found in 14 to 37-day Ss was unexpected. Polyak (1957, pp. 318-319) reports that guinea pigs have a proportion of optic uncrossed fibers even smaller than that of rats, and this should lead to low-level interocular transfer similar to that of albino rats, unless the central interhemispheric communication systems are more effective in guinea pigs. The latter possibility must be taken seriously, but it seems more likely that the contrast between guinea pig and albino rat interocular transfer performances is due to variations in ipsilateral fiber"system effectiveness. Guinea pigs have both a much larger absolute number of optic fibers and a greater proportion of myelinated fibers than do albino rats (Bruesch \& Arey, 1942). Hence, even a very small proportion of nondecussating fibers might be fairly effective in mediating pattern discrimination. More important, there is good reason to suspect that Polyak's estimate of the proportions of crossed and uncrossed fibers in guinea pigs is in error. Hess (1958) reported that fully $25 \%$ of the fibers fail to decussate. If Hess' figures are accurate, we can easily see how the development of the ipsilateral system might give rise to the interocular transfer functions reported in the present study, assuming that the central interhemispheric communication pathways are not capable of mediating full interocular transfer.

\section{References}

Bruesch, S. R., \& Arey, L. B. The number of myelinated and unmyelinated fibers in the optic nerve of vertebrates. $J$. comp. Neurol., 1942, 77, 631-635.

Hess, A. Optic centers and pathways after eye removal in fetal guinea pigs. J. comp. Neurol., 1958, 109, 91-115.

Lund, R. D. Uncrossed visual pathways of hooded and albino rats. Science, 1965, 149, 1506-1507.

Polyak, S. The vertebrate visual system. Chicago: University of Chicago Press, 1957.

Rose, G. H., \& Lindsley, D. B. Visually evoked electrocortical responses in kittens: development of specific and nonspecific systems. Science, 1965, 148, 1244-1246.

Sheridan, C. L. Interocular transfer of brightness and pattern discriminations in normal and corpus callosum-sectioned rats. $J$. comp. physiol. Psychol., 1965, 59, 292-294.

Sheridan, C. L., \& Shrout, L. L. Interocular transfer in the rat: the role of the occlusion process. Psychon. Sci., 1965, 2,173174.

Sheridan, C. L., \& Shrout, L. L. Differences in the effectiveness of optic uncrossed fiber systems in albino and hooded rats. Psychon. Sci., 1966, 4, 177-178.

\section{Note}

1. Supported by Grant MH-12268-01 from the U. S. Public Health Service to Charles L. Sheridan and by 8200 (Research) funds from the Veterans Administration. 